\title{
Sex Steroids Do Not Modulate TRPM2- Mediated Injury in Females following Middle Cerebral Artery Occlusion ${ }^{1,2,3}$
}

\author{
Nidia Quillinan,, ${ }^{1, *}$ Himmat Grewal,,,* Jelena Klawitter, ${ }^{1,2}$ and Paco S. Herson ${ }^{1,3}$
}

DOI:http://dx.doi.org/10.1523/ENEURO.0022-14.2014

${ }^{1}$ Department of Anesthesiology, University of Colorado School of Medicine, Aurora, Colorado 80045, ${ }^{2}$ Division of Renal Disease and Hypertension, University of Colorado School of Medicine, Aurora, Colorado 80045, ${ }^{3}$ Department of Pharmacology, University of Colorado School of Medicine, Aurora, Colorado 80045

\begin{abstract}
Calcium-permeable transient receptor potential M2 (TRPM2) ion channel activation contributes to cerebral ischemic injury specifically in males. In male mice, circulating androgens are required for TRPM2 inhibition with clotrimazole (CTZ) to provide protection following experimental stroke. Sufficient levels of circulating androgens are necessary to support ischemia-induced activation of poly ADP ribose polymerase (PARP) and consequent activation of TRPM2 channels. In this study, we tested whether differences in sex steroids contribute to the lack of CTZ neuroprotection in females. Middle cerebral artery occlusion (MCAO) was performed using adult female mice that were hormonally intact, ovariectomized (OVX) or dihydrotestosterone (DHT) treated. CTZ or vehicle was administered at the time of reperfusion, animals were euthanized $24 \mathrm{~h}$ later and brains and serum were collected. Infarct analysis revealed no effect of CTZ in intact females or females lacking endogenous sex steroids (OVX). Interestingly, treatment of female mice with the potent androgen receptor agonist DHT had no effect on ischemic injury and did not permit CTZ neuroprotection. Similarly, DHT-treated females did not exhibit increased levels of ADPribose, the TRPM2 ligand generated by PARP, following ischemia. No differences in TRPM2 or androgen receptor expression were observed between males and females. These data suggest that the lack of TRPM2 activation in females following experimental stroke is not due to the presence of estrogen or the absence of androgens. In conclusion, our data demonstrate that while circulating androgens are necessary for PARPmediated TRPM2 injury in males, they are not sufficient to produce TRPM2 activation in females.
\end{abstract}

Key words: androgens; gender; mouse; stroke; TRPM2

\section{Significance Statement}

TRPM2 is an ion channel that is activated by ischemia in stroke and contributes to neuronal injury only in males. We tested whether the lack of TRPM2 activation following stroke in females is caused by differences in sex steroids. Using adult female mice, we show that removal of female steroids or addition of males hormones fail to engage TRPM2-mediated injury. This study is an important negative preclinical study demonstrating that alterations in sex steroids fails to engage the TRPM2 cell death pathways in the female brain. 


\section{Introduction}

Transient receptor potential M2 (TRPM2) channels are nonselective cation channels that are permeable to $\mathrm{Na}^{+}$, $\mathrm{K}^{+}$, and $\mathrm{Ca}^{2+}$. The most well characterized role for the TRPM2 channel is its role in excessive $\mathrm{Ca}^{2+}$ influx following exposure of cells to oxidative stress, thus playing a pathological role in oxidative stress-induced cell injury (Kuhn et al., 2005; Miller, 2006; Miller and Zhang, 2011; Simon et al., 2013). Expression of TRPM2 channels in sensitive neuronal populations and channel activation following oxidative stress provided strong rationale for hypothesizing that TRPM2 channels are important mediators of brain injury following ischemia reperfusion (Szydlowska and Tymianski, 2010; Miller and Zhang, 2011). Indeed, inhibitors and knockdown of TRPM2 expression reduce ischemic injury following experimental stroke [middle cerebral artery occlusion (MCAO)] in the male brain, while having no effect in the female brain (Jia et al., 2011; Shimizu et al., 2013). A male-specific role of TRPM2 in ischemia-induced neuronal injury has also been demonstrated following global cerebral ischemia and in vitro (Verma et al., 2012; Nakayama et al., 2013). The focus of the current study is to test the hypothesis that hormonal differences in females underlie the lack of TRPM2 channel engagement following cerebral ischemia.

Stroke is well recognized as being a sexually dimorphic disease. Females have a lower incidence and better outcome from stroke compared to males into their menopausal years (Niewada et al.,2005; Herson et al., 2009; Herson and Hurn, 2010; Roof and Hall, 2000). Animal models of experimental stroke have been useful in examining gender differences in neurological injury and the role of sex steroids in modulating injury mechanisms. Interestingly, cell death pathways activated by ischemia are different between males and females (Lang and McCullough, 2008). Caspase-dependent cell death pathways are dominant in females (Liu et al., 2009), while oxidative stress-induced activation of poly ADP ribose polymerase (PARP) and stimulation of apoptosis-inducing factor is engaged in males (Yuan et al., 2009; Liu et al., 2011). Of particular relevance to the current study, PARPmediated damage following ischemia is male-specific and activation of PARP generates ADP ribose, which directly activates TRPM2 channels (Perraud et al., 2001; Fonfria

Received September 15, 2014; accepted November 11, 2014; First published November 12, 2014.

${ }^{1}$ The authors report no financial conflicts of interest.

${ }^{2}$ Author contributions: N.Q. and P.S.H. designed research; N.Q., H.G., and J.K. performed research; N.Q., H.G., and J.K. analyzed data; N.Q., J.K., and P.S.H. wrote the paper.

${ }^{3}$ Funding Sources: Funded in part by $\mathrm{NIH}$ Grant NS080851 and AHA 14GRNT18190012

${ }^{*}$ N.Q. and H.G. contributed equally to this work.

Correspondence should be addressed to Dr. Paco Herson, University of Colorado School of Medicine, 12800 E. 19th Avenue, Aurora, CO 80045. E-mail: paco.herson@ucdenver.edu.

DOI:http://dx.doi.org/10.1523/ENEURO.0022-14.2014

Copyright (C) 2014 Quillinan et al.

This is an open-access article distributed under the terms of the Creative Commons Attribution License Attribution-Noncommercial 4.0 International which permits noncommercial reuse provided that the original work is properly attributed. et al., 2004; Yuan et al., 2009; Vagnerova et al., 2010; Liu et al., 2011). Indeed, it was recently demonstrated that TRPM2 channel inhibition does not protect the male brain in the absence of PARP (Shimizu et al., 2013). Further, increased PARP activity and TRPM2-mediated cell death following experimental stroke requires the presence of circulating androgens in males (Shimizu et al., 2013). In contrast, it remains unclear what is responsible for the inability of ischemia to activate TRPM2 channels in the female brain. This study tests whether removal of estrogen or addition of androgens engages TRPM2-mediated injury mechanisms.

\section{Materials and Methods}

For all experiments, 8- to 12-week-old male and female (20-25 g) C57BL/6 mice (Charles River Laboratories) were used. All experiments were approved by the University of Colorado's Institutional Animal Care and Use Committee and were performed according to the guidelines from the National Institutes of Health. Mice were individually housed and allowed free access to food and water. All experiments were performed in a blinded randomized manner with a separate experimenter generating the experimental code.

\section{Ovariectomy and DHT implantation}

Surgical procedures were performed under isoflurane anesthesia $(1.5-3 \%)$. Ovariectomy (OVX) was performed 1 week prior to MCAO to allow for endogenous steroid levels to fall, as previously described (Dubal et al., 2001). For dihydrotestosterone (DHT) administration, implants were fabricated from silastic tubing $(3 \mathrm{~cm})$ filled with DHT powder (5 or $25 \mathrm{mg}$; Steraloids) and sealed with silicone rubber. Implants were allowed to dry overnight and were equilibriated in $0.9 \%$ saline for $12-16 \mathrm{~h}$ before implantation. One week prior to MCAO, implants were placed subcutaneously and wounds were closed with surgical clips. Animals were administered bupivacaine $(0.25 \mathrm{mg} / \mathrm{ml}$, s.c.) at the incision site for postoperative analgesia.

\section{Middle cerebral artery occlusion}

Transient focal cerebral ischemia was induced using the intraluminal filament technique to reversibly occlude the middle cerebral artery. Briefly, mice were anesthetized with isoflurane (induction $3.0 \%$ and maintenance $1.5-2.0 \%$ ), delivered through a face mask in oxygenenriched air. Head and body temperature were monitored and maintained at $36.5 \pm 0.5^{\circ} \mathrm{C}$ throughout the MCAO surgery with an electrical heating pad and heating lamp. A laser Doppler probe (Moor Instruments) was placed over the ipsilateral cortex to measure cerebral blood flow and assure adequate occlusion. Probe placement was established in a similar location for all mice by making a small incision (probe hole) in the middle of a line drawn between the outer canthus (lateral corner of the eye) and ear canal. All mice had a similar level of occlusion throughout, reduced to less than $30 \%$ of baseline obtained prior to filament occlusion. Clotrimazole $(30 \mathrm{mg} / \mathrm{kg})$ or vehicle (corn oil) was administered via subcutaneous injection 
(50 $\mu \mathrm{L} / 10 \mathrm{~g}$ body weight) $60 \mathrm{~min}$ after occlusion (at the time of reperfusion).

\section{Infarct analysis}

At $24 \mathrm{~h}$ after reperfusion, mice were anesthetized with isoflurane $(5.0 \%)$ and the animals were decapitated for brain removal. If hemorrhage was observed, the mouse was excluded from the study. A total of 117 mice were used in the study, with eight being excluded because of premature death, with no differences among groups. Brains were sliced into five 2-mm-thick coronal sections and were placed in a $1.2 \%$ solution of $2,3,5-$ triphenyltetrazolium chloride (TTC; Sigma) for $30 \mathrm{~min}$ at $37^{\circ} \mathrm{C}$ and fixed in $10 \%$ formalin for $24 \mathrm{~h}$. Both sides of each stained coronal slice were photographed using a digital camera (Leica Microsystems), and infarct volume was measured with Image $(\mathrm{NIH})$ and integrated across all five slices. To account for the effect of edema, the infarct volume of ipsilateral hemisphere was estimated indirectly and expressed as a percentage of the contralateral hemisphere.

\section{Quantitative real-time polymerase chain reaction}

TRPM2 mRNA expression was analyzed in nonsurgical hormonally intact adult males and females (8-12 weeks). Androgen receptor expression was analyzed in contralateral cortex at $24 \mathrm{~h}$ after MCAO. Animals were decapitated under isoflurane anesthesia, brains were rapidly removed, and cortices were isolated and rapidly frozen. Total RNA was isolated from approximately $10 \mathrm{mg}$ of cortical tissue (RNAqueous-4 PCR kit; Ambion) and eluted RNA was treated with DNAse (Ambion). First-strand cDNA was synthesized from 500 ng total RNA by reverse transcription using High Capacity cDNA Archive Kit (Applied Biosystems). Quantitative real-time polymerase chain reactions (qRT-PCR) were run in triplicate using SsoFast Mastermix (Biorad) on a Biorad CFX Connect real-time PCR system. FAM-labeled primer/probes used to detect mRNA transcripts of 18S, TRPM2, and the androgen receptor were synthesized by Applied Biosystems. Expression levels were calculated using the $\Delta \Delta \mathrm{C}_{\mathrm{T}}$ method relative to the internal control, $18 \mathrm{~S}$, and were normalized to male expression levels.

\section{ADP ribose measurements}

At $24 \mathrm{~h}$ after reperfusion, ADP ribose levels were measured in the cortical ipsilateral peri-infarct zone and the corresponding region from the contralateral cortex. ADP ribose was measured using tandem mass spectrometry (LC-MS/MS) as previously described. Briefly, peri-infarct and contralateral cortical tissues were obtained $24 \mathrm{~h}$ after reperfusion and homogenized in ice-cold $12 \%$ perchloric acid. Following neutralization (with $\mathrm{KOH}$ ) and lyophilization steps, samples were dissolved in water containing the internal standard $(1 \mu \mathrm{M}$ aminohexyl-ADP final concentration) and subjected to LC-MS/MS analysis. Agilent series 1100 HPLC (Agilent Technologies) coupled to an API4000 triple stage quadrupole mass spectrometer (AB Sciex) equipped with an electrospray ionization source (ESI) was employed for quantitation of ADP ribose according to the previously published method for quantita- tion of nucleotide monophosphates, diphosphates, and triphosphates (Klawitter et al., 2007). The following mass transitions [mass/charge ratio $(\mathrm{m} / \mathrm{z})]$ were used: ADP ribose (quantitation): $558.2 \rightarrow 345.9 ;$ ADP ribose (verification); $558.2 \rightarrow 210.7$; internal standard 6-aminohexyl-ADP: $525.0 \rightarrow 233.0$. Nebulizer gas was at 30 , and so was the heater gas (both nitrogen). The collision gas and curtain gas were at 10 and 20, respectively (both nitrogen). The source temperature was kept at $450{ }^{\circ} \mathrm{C}$. Data were acquired and processed for calibration and quantitation of all samples using the Analyst software 1.6.2. Data (in $\mathrm{ng} / \mathrm{mg}$ tissue) were presented as the ratio of peri-infarct/contralateral cortical values.

\section{DHT measurements}

At $24 \mathrm{~h}$ after reperfusion, DHT measurements were performed from serum collected by cardiac puncture. PBS $(150 \mu \mathrm{L})$ and water $(200 \mu \mathrm{L})$ were added to $50 \mu \mathrm{L}$ mouse serum sample, followed by the addition of $10 \mu \mathrm{L}$ d3-testosterone (internal standard, at $50 \mathrm{ng} / \mathrm{mL}$ ) and 2.5 $\mathrm{mL}$ of 2:1 chloroform/methanol extraction solution (modified Folch extraction method). After the vortex and centrifugation steps, the organic layer was dried in a vacuum concentrator, reconstituted in $300 \mu \mathrm{L}$ acetonitrile/water $(1: 1, v / v)$ and subjected to LC-MS/MS analysis. DHT measurements were performed on a Dionex Ultimate 3000 HPLC system (Thermo Scientific) that was connected to an API5500 QTRAP mass spectrometer (Absciex). The sample was loaded onto a XDB-C8 cartridge (Agilent) and washed with $20 \%$ methanol and $80 \% 0.1 \%$ formic acid (FA) for $0.7 \mathrm{~min}(2 \mathrm{~mL} / \mathrm{min})$. Thereafter, the switching valve was activated and the analytes were back-flushed with $98 \%$ methanol (at $100 \mu \mathrm{L} / \mathrm{min}$ ) from the extraction column onto the analytical column (XDB-C8 $3.5 \mu \mathrm{m}, 4.6 \times 150$ $\mathrm{mm}$; Agilent). The LC mobile phase consisted of $0.1 \%$ FA in water (mobile A) and methanol (mobile B). The following LC gradient was run at $1 \mathrm{~mL} / \mathrm{min}: 0-1.5 \mathrm{~min}: 60 \% \mathrm{mo}-$ bile B; $1.5-4.5 \mathrm{~min}: 60 \%$ to $98 \%$ mobile $\mathrm{B}$; 4.5 - 5.5 min: $98 \%$ mobile B; $5.5-5.6 \mathrm{~min}$ : $98 \%$ to $60 \%$ mobile B; $5.6-7$ min: held at $60 \%$ mobile B. MS data were acquired in positive ESI mode with an ion voltage of $5.5 \mathrm{kV}$. The following mass transitions $(\mathrm{m} / \mathrm{z})$ were used: DHT (quantitation): 291.2 $\rightarrow 255.2 ; \quad$ DHT (verification); $291.2 \rightarrow 159.2$; internal standard d3-testosterone: $292.2 \rightarrow 109.1$. Nebulizer gas and heater gas were at 45 (nitrogen). The collision gas and curtain gas were at medium and 15, respectively (both nitrogen). The source temperature was kept at $550^{\circ} \mathrm{C}$. Data were acquired and processed for calibration and quantitation of all samples using the Analyst software 1.5.2. Data levels (in $\mathrm{pg} / \mathrm{ml}$ ) were normalized to male DHT levels.

\section{Statistics}

All data are presented as means \pm SEM. Each $n$ represents an individual animal. Statistical comparisons between two groups was performed using Student's $t$ test (unpaired, two-tailed). Comparisons of multiple groups was performed using one-way ANOVA with Tukey's post hoc analysis. Statistical significance was set at $p<0.05$. Power analysis was performed in StatMate 2.0 (Graphpad) using $n$ and standard deviation of actual data 
Table 1 Statistical table

\begin{tabular}{|c|c|c|c|}
\hline & Data structure & Type of test & Power \\
\hline a & Normally distributed & One-way ANOVA; Sidak's post hoc & $60 \%$ \\
\hline$b$ & Normally distributed & One-way ANOVA; Sidak's post hoc & $80 \%$ \\
\hline c & Normally distributed & One-way ANOVA; Sidak's post hoc & $70 \%$ \\
\hline d & Normally distributed & One-way ANOVA; Sidak's post hoc & $70 \%$ \\
\hline e & Normally distributed & Student's t-test & $60 \%$ \\
\hline f & Normally distributed & Studen't t-test & $50 \%$ \\
\hline$g$ & Normally distributed & One-way ANOVA; Sidak's post hoc & $75 \%$ \\
\hline $\mathrm{h}$ & Normally distributed & One-way ANOVA; Sidak's post hoc & $70 \%$ \\
\hline i & Normally distributed & One-way ANOVA; Sidak's post hoc & $60 \%$ \\
\hline j & Normally distributed & One-way ANOVA; Sidak's post hoc & $50 \%$ \\
\hline $\mathrm{k}$ & Normally distributed & One-way ANOVA; Sidak's post hoc & $50 \%$ \\
\hline I & Normally distributed & One-way ANOVA; Tukey's post hoc & $70 \%$ \\
\hline $\mathrm{m}$ & Normally distributed & One-way ANOVA; Tukey's post hoc & $75 \%$ \\
\hline$n$ & Normally distributed & One-way ANOVA; Tukey's post hoc & $60 \%$ \\
\hline 0 & Normally distributed & One-way ANOVA; Tukey's post hoc & $50 \%$ \\
\hline$p$ & Normally distributed & One-way ANOVA; Tukey's post hoc & $20 \%$ \\
\hline q & Normally distributed & Student's t-test & $60 \%$ \\
\hline r & Normally distributed & Student's t-test & $60 \%$ \\
\hline
\end{tabular}

Lines refer to the alphabetical value provided in the Results section. Power calculations were performed in StatMate using the $n$ and standard deviations from data sets being analyzed and the smallest difference between means that is scientifically relevant. For infarct analysis, a delta of 10 was used. For qPCR data sets delta $=0.3$. For ADP ribose and DHT data sets delta $=1.0$.

(Table 1, superscript letters in the Results indicate rows in the table).

\section{Results}

MCAO (60 min) was performed on adult male and female mice. The TRPM2 inhibitor clotrimazole (CTZ; 30 $\mathrm{mg} / \mathrm{kg}$, s.c.) or vehicle were administered at the time of reperfusion. Mice were euthanized $24 \mathrm{~h}$ after MCAO and TTC staining was performed on $2 \mathrm{~mm}$ brain sections (Fig. 1A). Infarct volume was smaller in CTZ-treated males (26.11 $\pm 2.25 \%$ of hemisphere, $n=8)$ compared to vehicle-treated males $(38.98 \pm 3.7 \% ; n=8 ; p=0.02)^{a}$ (Fig. 1B). In contrast, CTZ had no effect on infarct volume in intact female mice $(29.85 \pm 2.04 \%, n=12$ and $30.24 \pm$ $2.83, n=11, p=0.99$, respectively) ${ }^{\mathrm{b}}$. Infarct volumes in

A

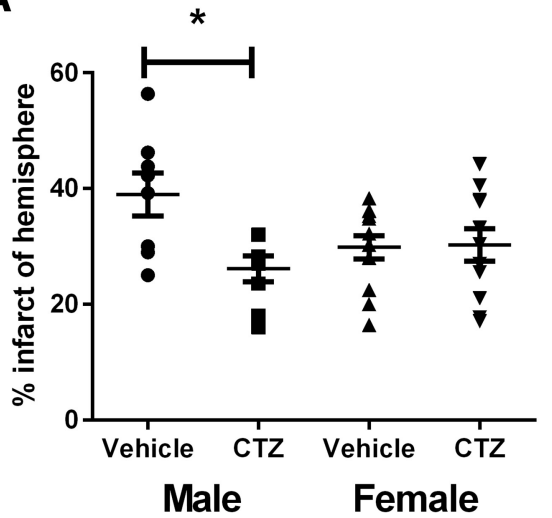

vehicle-treated male and females were not significantly different (male vehicle vs female vehicle: $p=0.09^{c}$; male CTZ vs female CTZ: $p=0.76^{\mathrm{d}}$ ). The lack of protection observed in CTZ-treated female mice is not the result of reduced expression in females as mRNA levels of TRPM2 transcript were not different from males (1.000 $\pm 0.07692, n=4)$ and females $(1.274 \pm 0.1219, n=5$; $\left.p=0.11^{\mathrm{e}}\right)$.

To investigate whether circulating female hormones prevent TRPM2 activation, female mice were ovariectomized. MCAO was performed 1 week after OVX to allow for depletion of hormones (Dubal et al., 2001) and CTZ or vehicle were administered at the time of reperfusion. Infarct was analyzed $24 \mathrm{~h}$ after MCAO. Consistent with
B

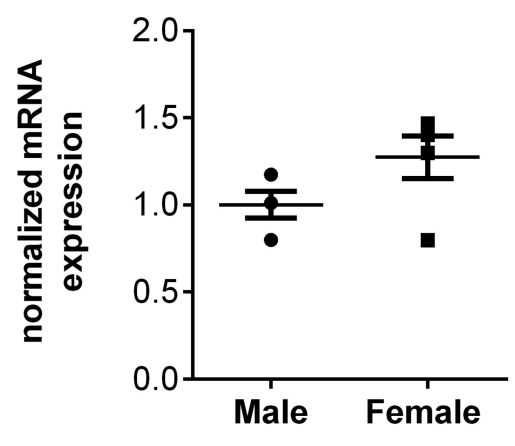

Figure 1 Clotrimazole is neuroprotective specifically in males. $\boldsymbol{A}, \mathrm{TTC}$ staining and infarct analysis was performed $24 \mathrm{~h}$ after MCAO and presented as the percentage of corrected hemisphere. Clotrimazole administered at the time of reperfusion caused a significant reduction in infarct size in males but not females. Bars represent mean \pm SEM. Comparisons made using one-way ANOVA and Tukey's post $h o c$ analysis; $* p=0.02 B$, TRPM2 mRNA expression was measured by qRT-PCR and quantified relative to the housekeeping gene 18s. Data were normalized to male TRPM2 expression levels. No significant differences in TRPM2 mRNA were observed between males and females (Student's $t$ test; $p=0.12$ ). 


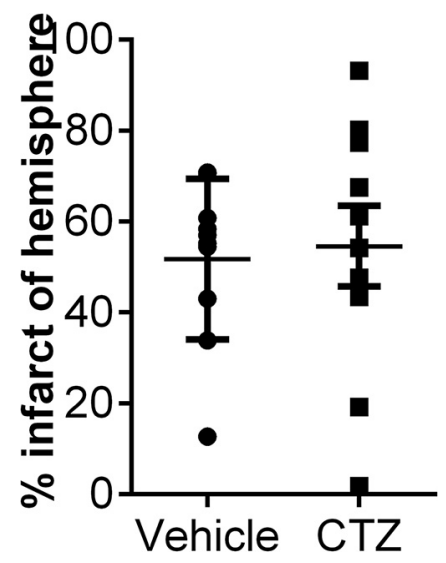

Figure 2 Clotrimazole administered to overarectomized females fails reduce infarct size. Female mice were ovarectomized and MCAO was performed $7 \mathrm{~d}$ later. Infarct analysis $24 \mathrm{~h}$ after MCAO revealed no difference between vehicle- and CTZ-treated females (Student's $t$ test; $p=0.79$ ).

extensive literature demonstrating a protective effect of endogenous estrogen (Alkayed et al., 1998; Fukuda et al., 2000; Herson et al., 2009), we observed significant increase in infarct volume in OVX mice compared to intact females $\left(p=0.0008^{f}\right)$. However, CTZ administered at the time of reperfusion had no effect on infarct volume in OVX females compared to vehicle-treated OVX females (vehicle: $51.69 \pm 5.59 \%$; CTZ: $54.58 \pm 8.88 \%, n=10, p=$ $0.79^{9}$ ) (Fig. 2).

We next tested whether the lack of TRPM2 activation in females is due to relatively low levels of androgens compared to males. Females received subcutaneous implants of the potent androgen DHT, which is not metabolized to estrogen. We chose doses ( 5 and $25 \mathrm{mg}$ ) that have been used previously to modulate injury in the male (Uchida et al., 2009; Nakano et al., 2010; Dziennis et al., 2011). Sham groups received empty implants. MCAO was performed 1 week after implantation. As shown previously, no effect of CTZ was observed in females with empty implants. DHT administered to females had no effect on infarct volume compared to sham females (Sham + vehicle: $29.85 \pm 2.04 \%, n=12$; $5 \mathrm{mg} / \mathrm{kg}$; DHT+vehicle: $28.73 \pm 3.07 \%, n=11, p>$ $.0 .99^{\mathrm{h}} ; 25 \mathrm{mg} / \mathrm{kg}$ DHT+vehicle: $29.17 \pm 4.22, n=7, p>$ 0.99') (Fig. 3A). In females that received DHT implants, CTZ administered at the time of reperfusion did not alter infarct size relative to vehicle-treated group $(5 \mathrm{mg} / \mathrm{kg}$ DHT+CTZ: $26.95 \pm 4.5, n=12, p>0.99$ compared with $5 \mathrm{mg} / \mathrm{kg}$ DHT+vehicle ; $25 \mathrm{mg} / \mathrm{kg}$ DHT+CTZ: $36.46 \pm 2.4$, $n=8, p=0.65$ compared with $25 \mathrm{mg} / \mathrm{kg} \mathrm{DHT}+$ vehicle $^{\mathrm{k}}$ ) (Fig. 3B).

Serum DHT levels $24 \mathrm{~h}$ after MCAO were measured from males and sham- and DHT-implanted females. DHT levels in sham-implanted females $(0.85 \pm 0.05, n=5)$ were similar to males $\left(1.0 \pm 0.18, n=6 ; p=0.98^{\prime}\right)$. DHT levels in females receiving $5 \mathrm{mg} / \mathrm{kg}$ DHT were not significantly different from males or sham-implanted females $\left(1.69 \pm 0.22, n=7 ; p=0.29^{\mathrm{m}}\right.$ vs males and $p=0.19^{\mathrm{n}}$ vs sham females). DHT levels in females that received 25 $\mathrm{mg} / \mathrm{kg} \mathrm{DHT}$ were significantly higher than all other groups $\left(3.7 \pm 0.46, n=6 ; p<0.01^{\circ}\right)$ (Fig. 4A). To assess androgen receptor expression in males and females, qRTPCR was performed on RNA isolated from contralateral cortical tissue collected $24 \mathrm{~h}$ after MCAO. Expression levels were quantitated relative to 18s RNA and normalized to male expression. Relative androgen receptor mRNA levels in sham females were $7.7 \pm 1.2(n=5)$ and $9.7 \pm 1.7(n=5)$ in DHT-treated females $(25 \mathrm{mg} / \mathrm{kg})$, significantly higher than males $\left(1 \pm 0.27 ; p<0.0008^{\mathrm{P}}\right)$ (Fig. 4B).

We next assessed the effect of ischemia on brain levels of the TRPM2 activator ADP ribose, measured by LCMS/MS in peri-infarct cortex and normalized to corresponding contralateral cortex levels. Ischemia did not cause an increase in ADP ribose levels in sham-implanted females $24 \mathrm{~h}$ after MCAO $\left(p=0.90^{\circ}\right.$, contralateral compared to peri-infarct), confirming our previously published results. Similarly, females treated with the high dose of
A

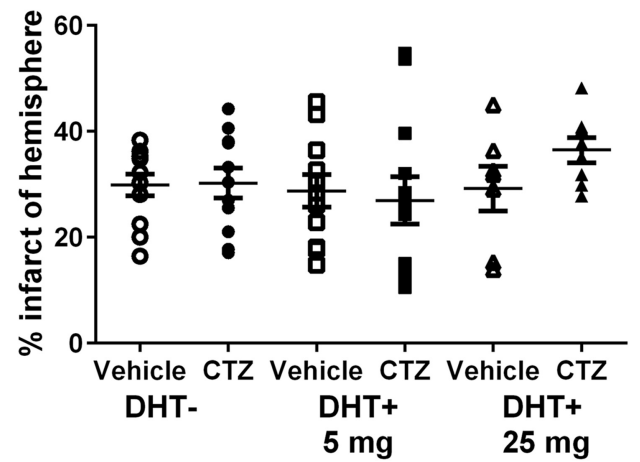

B

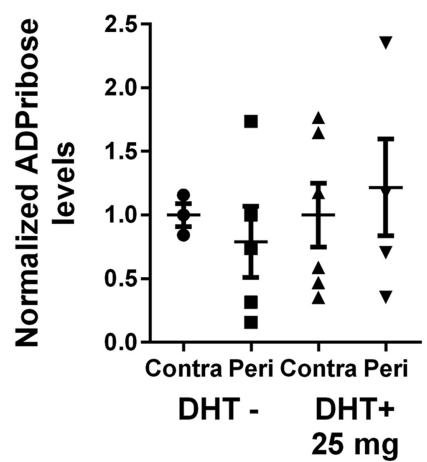

Figure 3 Administration of DHT fails to engage TRPM2 activation following cerebral ischemia. $\boldsymbol{A}$, Mice were implanted with DHT (0, 5 , or $25 \mathrm{mg}$ ) and MCAO was performed 1 week later. Infarct anlaysis showed no effect of CTZ administered at the time of reperfusion on infarct volume (one-way ANOVA; $p=0.83$ ). $\boldsymbol{B}$, Mass spectrometry performed on cortical tissue collected $24 \mathrm{~h}$ after MCAO revealed no relative increase in ADP ribose in peri-infarct cortex relative to contralateral hemisphere in $\mathrm{DHT}-$ or $\mathrm{DHT}+$ groups (one-way ANOVA; $p=0.27$. 
A

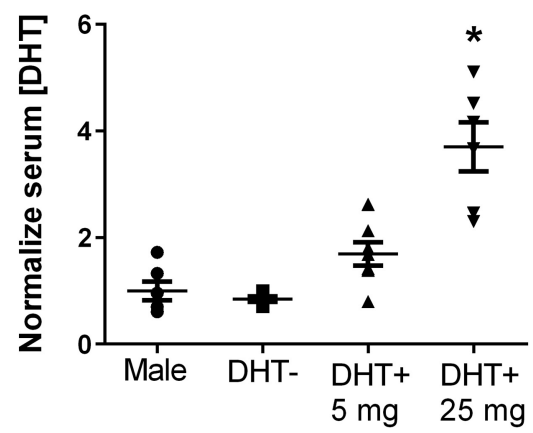

B

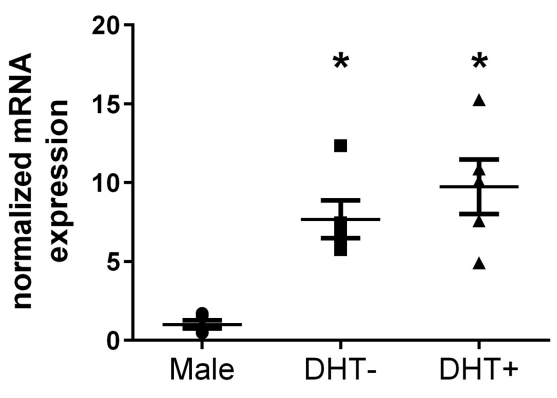

Figure 4 Serum DHT levels and androgen receptor expression. $\boldsymbol{A}$, Serum DHT levels were measured in males and DHT-/+ females $24 \mathrm{~h}$ after MCAO by LC/MS. Females receiving DHT $(25 \mathrm{mg})$ had significantly higher levels of DHT than all other groups (one-way ANOVA; $p<0.0001)$. $B$, Androgen receptor expression was measured by qRT-PCR and revealed that female mRNA levels were higher than those in males (one-way ANOVA; $p=0.0008$ ) $*$ indicates $p<0.05$.

DHT (25 mg/kg) also failed to exhibit an ischemia-induced increase in ADP ribose levels in peri-infarct cortex $(p=$ 0.97 ) (Fig. 3B).

\section{Discussion}

The results of this study suggest that the lack of TRPM2mediated injury mechanisms in females is not the result of differences in sex steroids. Neither removal of estrogen nor addition of androgens was capable of engaging TRPM2-mediated injury following experimental stroke in female animals. It has been previously reported that circulating androgens were required for PARP-mediated TRPM2 activation in males (Shimizu et al., 2013). Therefore, we predicted that administration of DHT to females would permit PARP-mediated increases in ADP ribose levels and subsequent TRPM2 activation. The lack of ADP ribose increase and TRPM2-mediated injury in DHTtreated females, combined with similar expression levels of TRPM2 in males and females, suggests there are signaling pathways that prevent PARP activation in females, but that are not related to circulating steroid levels.

Gender differences in infarct size following stroke have been well documented in both clinical and animal studies. Many of the gender differences observed between young adult males and females can be attributed to endogenous circulating sex steroids (Hurn and Macrae, 2000; McCullough and Hurn, 2003; Herson et al., 2009; Liu et al., 2010). Several studies have demonstrated that reduction of endogenous female steroids by ovariectomy causes an increase in neuronal injury following experimental ischemia in young adult females (Alkayed et al., 1998; Fukuda et al., 2000). Data presented in the current study is consistent with this body of literature, as we observed a significant increase in infarct volume in OVX females compared to intact females. Numerous mechanisms underlying the relative protection afforded females by endogenous sex steroids have been identified, including inhibition of excitotoxicity, oxidative stress, and apoptotic cell death pathways, as well as activation of antiapoptotic signaling (McCullough and Hurn, 2003; Lebesgue et al., 2009; Liu et al., 2009). Our data indicates that inhibition of TRPM2 channels is not among these mech- anisms. We did not observe protection following inhibition of TRPM2 channels with CTZ in OVX females. This suggests that female sex steroids are not preventing the activation of TRPM2-mediated injury mechanisms.

TRPM2-mediated neuronal injury following cerebral ischemia has been shown to be a male-specific cell death pathway (Jia et al., 2011; Verma et al., 2012; Nakayama et al., 2013; Shimizu et al., 2013). Previous in vitro studies have demonstrated a similar level of TRPM2 expression in sex-stratified cultures (Nakayama et al., 2013). Our current study is in agreement with these earlier in vitro observations, observing that TRPM2 mRNA levels are similar in intact males and females. This suggests that channel activation, rather than expression, accounts for gender differences in CTZ protection. Indeed, it was recently reported that CTZ protection is observed in female cultures exposed to oxidative stress with hydrogen peroxide and application of ADP ribose to female neurons results in TRPM2-mediated depolarization (Nakayama et al., 2013). Therefore, it appears that the female brain expresses similar levels of TRPM2 channels and under certain circumstances TRPM2 channels can be activated in the female, resulting in neuronal injury. However, ischemia does not provide a sufficient stimulus to active TRPM2 channels in the female brain. The simplest explanation is the relative lack of PARP-mediated generation of ADP ribose in the female brain following cerebral ischemia. Indeed, it was recently reported that experimental stroke does not activate PARP or enhance ADP ribose levels in the intact female brain (Shimizu et al., 2013). Consistent with this recent report, we do not observe increased levels of ADP ribose in the peri-infarct region in females. In males, the increased PARP activity/ADP ribose levels and subsequent TRPM2-mediated injury was androgendependent (Shimizu et al., 2013). Based on results in castrated males, we hypothesized that androgenmediated signaling accounts for gender differences in TRPM2 activation following cerebral ischemia. Our results with DHT-treated females lacking CTZ protection suggest that circulating androgens are not sufficient to engage PARP-mediated TRPM2 activation in females. Indeed, we 
failed to observe relative changes in ADP ribose in females with or without DHT treatment. The lack of TRPM2 engagement in DHT-treated females is not due to insufficient levels of androgens or the androgen receptors. We observed significantly elevated levels of DHT in females treated with $25 \mathrm{mg} \mathrm{DHT}$ and females had much higher mRNA expression of the androgen receptor than males. We did not observe a difference in plasma DHT levels in male and female postischemic animals. This observation is consistent with recent reports demonstrating a dramatic decrease in androgens in males following ischemic stroke (Dash et al., 1991; Jeppesen et al., 1996). Therefore, it appears that the lack of PARP activation in the female brain is not related to insufficient levels of androgens, which is in direct contrast to our previous results in males demonstrating that androgens are necessary for PARP and TRPM2 activation.

The fundamental role of female sex steroids in shaping ischemic sensitivity implicates them in the modulation of cell death mechanisms. However, results from the current study emphasize the importance of considering sexspecific factors independent of circulating sex steroids when assessing mechanisms of neuroprotection in preclinical studies. The lack of protection observed in OVX and DHT-treated female mice administered with the TRPM2 inhibitor CTZ is surprising and suggests other factors prevent engagement of this pathway in females. It is possible that acute changes in sex steroids used in this study are not sufficient to overcome hormonal imprinting that may occur during early development and puberty. Males experience a surge in circulating androgens during early postnatal development that may determine later signal transduction capacity of the cell (Knickmeyer and Baron-Cohen, 2006; Courant et al., 2010; Persky et al., 2013). Similarly, the postpubertal increase in circulating steroids in males and females may impact cell death mechanisms in a manner that is not easily altered by manipulating steroids in adulthood. There is increasing evidence that genetic sex ( $X X$ vs $X Y$ ) shapes cell death mechanisms and contributes to oxidative stress pathways being the dominant cell death pathway in males and caspase-dependent pathways being dominant in females (Lang and McCullough, 2008; Liu et al., 2009; Yuan et al., 2009). Indeed, we have observed sex differences in estrogen neuroprotection in prepubertal juvenile mice subjected to MCAO, suggesting that sex differences in ischemic injury may already be established at this stage of development (Herson et al., 2013). Therefore, it is likely that ischemic outcome and cell death mechanisms are influenced by the complex interaction of innate sex and hormonal influences. These complex interactions are certainly worthy of study; however, they are beyond the scope of the present study. Nonetheless, our current data indicating the lack of influence of sex steroids on the TRPM2 cell death pathway has important implications when considering the treatment of postmenopausal women after stroke. It could have been expected that due to the decline in estrogen, injury mechanisms in the postmenopausal female would resemble the male response to ischemia; however, this hypothesis is not supported by the current study.

Male-specific protection following inhibition or genetic deletion of PARP-1 has been well described (Yuan et al., 2009; Vagnerova et al., 2010; Liu et al., 2011; Shimizu et al., 2013). In fact, PARP-1 knock-out (KO) female mice exhibit enhanced ischemic injury compared to wild-type mice. Similarly, nitric oxide synthase (NOS) KO mice reveal a sexually dimorphic role of NOS, with males exhibiting less neuronal injury in female NOS KO mice (McCullough et al., 2005). Thus, it appears that males generate more reactive oxygen species (ROS) and are more sensitive to ROS-mediated injury compared with females (Lang and McCullough, 2008). The data generated by this study and previously are consistent with this model, as the oxidative-stress-sensitive ion channel TRPM2 is engaged preferentially in the male brain following ischemia. The current study furthers the hypothesis that TRPM2 channels are downstream of PARP and thus conditions that fail to activate PARP also do not engage TRPM2 channels. However, it remains possible that additional factors are involved in preventing ischemiainduced activation of TRPM2 channels in the female brain. TRPM2 channels have been demonstrated to be activated by O-actyl-ADP ribose generated by sirtuins (Grubisha et al., 2006) and thus it is possible that sirtuin activation is sexually dimorphic. Similarly, TRPM2 channel activity was recently shown to be modulated by EFHC1 (Katano et al., 2012), making this another candidate for sexually dimorphic regulation of channel activity. While the current study provides important new information regarding the role of sex steroids in TRPM2 channel regulation in the female brain, further studies are needed to understand the lack of activation of TRPM2 channels in the female brain following cerebral ischemia.

\section{References}

Alkayed NJ, Harukuni I, Kimes AS, London ED, Traystman RJ, Hurn PD (1998) Gender-linked brain injury in experimental stroke. Stroke 29:159-166.

Courant F, Aksglaede L, Antignac JP, Monteau F, Sorensen K Andersson AM, Skakkebaek NE, Juul A, Bizec BL (2010) Assessment of circulating sex steroid levels in prepubertal and pubertal boys and girls by a novel ultrasensitive gas chromatography-tandem mass spectrometry method. J Clin Endocrinol Metab 95:82-92. CrossRef

Dash RJ, Sethi BK, Nalini K, Singh S (1991) Circulating testosterone in pure motor stroke. Funct Neurol 6:29-34. Medline

Dubal DB, Zhu H, Yu J, Rau SW, Shughrue PJ, Merchenthaler I, Kindy MS, Wise PM (2001) Estrogen receptor $\alpha$, not $\beta$, is a critical link in estradiol-mediated protection against brain injury. Proceed Nat Acad Sci U S A 98:1952-1957. CrossRef Medline

Dziennis S, Akiyoshi K, Subramanian S, Offner H, Hurn H (2011) Role of dihydrotestosterone in post-stroke peripheral immunosuppression after cerebral ischemia. Brain Behav Immun 25:685-695. CrossRef Medline

Fonfria E, Marshall IC, Benham CD, Boyfield I, Brown JD, Hill K, Hughes JP, Skaper SD, McNulty S (2004) TRPM2 channel opening in response to oxidative stress is dependent on activation of poly(ADP-ribose) polymerase. $\mathrm{Br} J$ Pharmacol 143:186-192. CrossRef Medline

Fukuda K, Yao H, Ibayashi S, Nakahara T, Uchimura H, Fujishima M (2000) Ovariectomy exacerbates and estrogen replacement atten- 
uates photothrombotic focal ischemic brain injury in rats. Stroke 31:155-160. CrossRef

Grubisha O, Rafty LA, Takanishi CL, Xu X, Tong L, Perraud AL, Scharenberg AM, Denu JM (2006) Metabolite of SIR2 reaction modulates TRPM2 ion channel. J Biol Chem 281:14057-14065. CrossRef Medline

Herson PS, Hurn PD (2010) Gender and the injured brain. Prog Brain Res 186:177-187. CrossRefMedline

Herson PS, Koerner IP, Hurn PD (2009) Sex, sex steroids, and brain injury. Semin Reprod Med 27:229-239. CrossRef Medline

Herson PS, Bombardier CG, Parker SM, Shimizu T, Klawitter J, Klawitter J, Quillinan N, Exo JL, Goldenberg NA, Traystman RJ (2013) Experimental pediatric arterial ischemic stroke model reveals sex-specific estrogen signaling. Stroke 44:759-763. CrossRef

Hurn PD, Macrae IM, (2000) Estrogen as a neuroprotectant in stroke. J Cereb Blood Flow Metab 20:631-652. CrossRef Medline

Jeppesen LL, Jørgensen HS, Nakayama H, Raaschou HO, Olsen TS, Winther K (1996) Decreased serum testosterone in men with acute ischemic stroke. Arterioscler Thromb Vasc Biol 16:749-754. Medline

Jia J, Verma S, Nakayama S, Quillinan N, Grafe MR, Hurn PD, Herson PS (2011) Sex differences in neuroprotection provided by inhibition of TRPM2 channels following experimental stroke. J Cereb Blood Flow Metab 31:2160-2168. CrossRef Medline

Katano M, Numata T, Aguan K, Hara Y, Kiyonaka S, Yamamoto S, Miki T, Sawamura S, Suzuki T, Yamakawa K, Mori Y (2012) The juvenile myoclonic epilepsy-related protein EFHC1 interacts with the redox-sensitive TRPM2 channel linked to cell death. Cell Calcium, 51:179-185. CrossRef Medline

Klawitter J, Schmitz V, Klawitter J, Leibfritz D, Christians U (2007) Development and validation of an assay for the quantification of 11 nucleotides using LC/LC-electrospray ionization-MS. Anal Biochem 365:230-239. CrossRef Medline

Knickmeyer RC, Baron-Cohen S, (2006) Fetal testosterone and sex differences. Early Hum Dev 82:755-760. CrossRef Medline

Kuhn FJ, Heiner I, Lückhoff A (2005) TRPM2: a calcium influx pathway regulated by oxidative stress and the novel second messenger ADP-ribose. Pflugers Arch 451:212-219. CrossRef Medline

Lang JT, McCullough LD (2008) Pathways to ischemic neuronal cell death: are sex differences relevant? J Transl Med 6:33. CrossRef

Lebesgue D, Chevaleyre V, Zukin RS, Etgen AM (2009) Estradiol rescues neurons from global ischemia-induced cell death: multiple cellular pathways of neuroprotection. Steroids 74:555-561. CrossRef Medline

Liu F, Li Z, Li J, Siegel C, Yuan R, McCullough LD, (2009) Sex differences in caspase activation after stroke. Stroke 40:18421848. CrossRef Medline

Liu F, Lang J, Li J, Benashski SE, Siegel M, Xu Y, McCullough LD (2011) Sex differences in the response to poly(ADP-ribose) polymerase-1 deletion and caspase inhibition after stroke. Stroke 42:1090-1096. CrossRef Medline

Liu M, Kelley MH, Herson PS, Hurn PD (2010) Neuroprotection of sex steroids. Minerva Endocrinol 35:127-143. Medline

McCullough LD, Hurn PD (2003) Estrogen and ischemic neuroprotection: an integrated view. Trends Endocrinol Metab 14:228-235. Medline
McCullough LD, Zeng Z, Blizzard KK, Debchoudhury I, Hurn PD (2005) Ischemic nitric oxide and poly (ADP-ribose) polymerase-1 in cerebral ischemia: male toxicity, female protection. J Cereb Blood Flow Metab 25:502-512.

Miller BA (2006) The role of TRP channels in oxidative stress-induced cell death. J Membr Biol 209:31-41. CrossRef Medline

Miller BA, Zhang W (2011) TRP channels as mediators of oxidative stress. Adv Exp Med Biol 704:531-544. CrossRef Medline

Nakano T, Hurn PD, Herson PS, Traystman RJ (2010) Testosterone exacerbates neuronal damage following cardiac arrest and cardiopulmonary resuscitation in mouse. Brain Res 1357:124130.CrossRef

Nakayama S, Vest R, Traystman RJ, Herson PS (2013) Sexually dimorphic response of TRPM2 inhibition following cardiac Arrestinduced global cerebral ischemia in mice. J Mol Neurosci 51:9298. CrossRef Medline

Niewada M, Kobayashi A Sandercock PA, Kamiński B, Członkowska A (2005) Influence of gender on baseline features and clinical outcomes among 17,370 patients with confirmed ischaemic stroke in the international stroke trial. Neuroepidemiology 24:123128. CrossRef

Perraud AL, Fleig A, Dunn CA, Bagley LA, Launay P, Schmitz C, Stokes AJ, Zhu Q, Bessman MJ, Penner R, Kinet JP, Scharenberg AM (2001) ADP-ribose gating of the calcium-permeable LTRPC2 channel revealed by nudix motif homology. Nature 411:595-599. CrossRef Medline

Persky RW, Liu F, Xu Y, Weston G, Levy S, Roselli CE, McCullough LD (2013) Neonatal testosterone exposure protects adult male rats from stroke. Neuroendocrinology 97:271-282. CrossRef Medline

Roof RL, Hall ED (2000) Gender differences in acute CNS trauma and stroke: neuroprotective effects of estrogen and progesterone. $\mathrm{J}$ Neurotrauma 17:367-388.

Shimizu T, Macey TA, Quillinan N, Klawitter J, Perraud AL, Traystman RJ, Herson PS (2013) Androgen and PARP-1 regulation of TRPM2 channels after ischemic injury. J Cereb Blood Flow Metab 33: 1549-1555. CrossRef Medline

Simon F, Varela D, Cabello-Verrugio C (2013) Oxidative stressmodulated TRPM ion channels in cell dysfunction and pathological conditions in humans. Cell Signal 25:1614-1624. CrossRef Medline

Szydlowska K, Tymianski M (2010) Calcium, ischemia and excitotoxicity. Cell Calcium 47:122-129. CrossRef Medline

Uchida M, Palmateer JM, Herson PS, DeVries AC, Cheng J, Hurn PD (2009) Dose-dependent effects of androgens on outcome after focal cerebral ischemia in adult male mice. $\mathrm{J}$ Cereb Blood Flow Metab 29:1454-1462. CrossRef Medline

Vagnerova K, Liu K, Ardeshiri A, Cheng J, Murphy SJ, Hurn PD, Herson PS (2010) Poly (ADP-ribose) polymerase-1 initiated neuronal cell death pathway-do androgens matter? Neuroscience 166: 476-481.

Verma S, Quillinan N, Yang Y, Nakayama S, Cheng J, Kelley MH, Herson PS (2012) TRPM2 channel activation following in vitro ischemia contributes to male hippocampal cell death. Neurosci Lett 530:41-46.

Yuan M, Siegel C, Zeng Z, Li J, Liu F, McCullough LD (2009) Sex differences in the response to activation of the poly (ADP-ribose) polymerase pathway after experimental stroke. Exp Neurol 217: 210-218. CrossRef Medline 